gained by reverting to the cow, those gentlemen who have obtained virus from me since May, 1836, have the full benefit of it, and to them it may be gratifying to learn the origin of what $I$ have put into their hands. I am, Sir, with respect, yours,

Baker-street, July 8, 1839. Foward LeEse.

\section{UTERINE HEMORRHAGE.}

\section{To the Ealitor of The LANCET.}

SrR:-Should the following case be deemed worthy a corner in THE LANCET, or the suggestion prove serviceable to my medical brethren, to whom a similar case may occur (without the immediate reach of medicine), I shall feel fully recompensed. I am, Sir, your obedient servant,

W. B. Parkes, M.R.C.S.L.

42, Carnaby-street, Golden-square, July 8,1839 .

Late in the evening of the 24th plt. I was summoned to attend the accouchment of a female who was much debilitated, from hard work and poverty, and who had previously borne four children. Immediately after delivery profuse bæmorrbage enswed. I found it necessary to extract the placenta, and after employing the customary means the uterus contracted, and the hæmorrhage ceased. Having previously administered an opiate, I left ber, leaving strict injunctions that she should not be moved until I saw her again. The nurse being over officious, thought it necessary to the patient's comfort that the "bed should be eused;" for which purpose she was placed in a chair by the bed-side. This proceeding, as you may expect, brought on the h emorrhage; I was immediately sent for, but being in attendance at some distance, considerable delay took place before my arrival. I found the unfortunate woman apparently sinking from loss of blood. I administered a slight stimulant in order to resuscitate my patient, and dashed cold water on the abdomen. The uterus was perfectly flaccid; I introduced my haad in order to excite contraction, but without effect. Now, as there was no time to be lost, and as the messenger whom I had dispatched to my house had not returned, it occurred to me that if $I$ could possibly cause the abdominal muscles to contract, they would probably act on the uterus, and so tend to allay this frightful hæmorrhage. Well, I immediately excited the fauces by means of a feather, which occasioned a pretty considerable retching; and in the space of a very short time the abdominal muscles acted upon the uterus, caused it to contract, and thus, to my great joy, arrested the hamorrhage, of which there has been no return. The patient is doing well, and with a little care will be able to resume her occupation.

\section{ARTIFICIAL ANUS MADE IN THE GROIN, WITH SUCCESS.}

Tre folluwing case may serve as a companion to the one related by $M$. Amussat, and published in our last Number :-

An infant three days old did not present any traces of the anal opening. The raphé of the perineum extended withont interruption from the scrotum to the point of the coccyx. The abdomen was tender and tympanitic, but there was no vomiting. The infant had taken the breast several times, and had passed its urine without difficulty. An incision of several lines in length was made over the supposed situation of the anus, and carried to the depth of three quarters of an inch or more, but without success. It was decided then to open the cæcum in the right iliac fossa. An incision was made near the anterior iliac spine; a small knuckle of in. testine presented itself, which was replaced, and the cæcum was found without difficulty. It was opened, and several ounces of meconium immediately escaped, followed by 2 remarkable amelioration of the symptoms. The progress towards cure was very rapid; the alvine evacuations continued to be pass. ed by the artificial opening, and on the eighth day after the operation the sutures were removed.-(Medizinische Zeitung für Heilkunde in Preusen.)-British and Foreigu Quarterly.

\section{INFLUENCE OF CIVILISATION IN THE PRODUCTION OF INSANITY.}

Is an elaborate article on this subject, published in the last number of the "Annales d'Hygiene Publique," M. Brierre de Boismont has announced the following propositions :-

Insanity is more frequent, and its forms more diversified, in proportion to the degree of civilisation to which each nation has attained. It becomes more rare as the nation approaches the savage state.

In civilised nations, insanity commonly depends on moral causes; in uncivilised nations, on physical causes.

At different epochs and in different coun. tries there arise various epidemic forms of insanity determined by the influence of the dominant ideas of the time.

Any remarkable event, or any great public calamity, is sure to augment the number of deranged persons for the time being.

The increase in the number of insane persons follows closely on the development of the intellectual faculties, passions, industry, wealth, and misery.

Insanity being thus shown to depend, in a great measure, on moral causes, and to be 